\title{
Tarihte ve Günümüzde Ehl-i Sünnet Sempozyumu
}

\section{Giriş}

03-05 2004'de İsâmî İlimler Araştırma Vakfı tarafından organize edilen "Tarihte ve Günümüzde Ehl-i Sünnet" adlı sempozyum, yurt içinden ve yurt dışından katılan kırk kişilik ilim adamı tarafından İstanbul'da gerçekleştirilmiştir.

Diyanet İşleri Başkani'nun açllş̧ konuşmasıyla başlayan ve 3 gün süren sempozyumda, 7 oturumda, 10 tebliğ sunuldu. Her tebliğden sonra tebliğle ilgili görüss ve sorulara yer verildi, ve üçüncü günün sonunda genel bir değerlendirme yapıldı. Vakıf başkanı Ali Özek'in, itikadın önemine işaret ettiği konuşmasının ardından birinci oturuma geçildi.

\section{Tanttım}

Prof. Dr. Salih Tuğ başkanlığında yapılan birinci oturumda Prof. Dr. Mevlüt Özler, "Ehlü's-Sünne ve'l-Cemâ'a'nın Oluşum Süreci, Tarihsel - Teolojik Bağlamı ve Kimliği Sorunu" adlı bir tebliğ sundu. Ehl-i Sünnet ve'l-Cemaat kavramınun, sosyolojik bir kavram olduğunu ifade eden Özler, sünnet ve cemaat kelimelerinin Kur'an ve Sünnet'te ayn yerlerde bulunmakla birlikte, Ehl-i Sünnet ve'l-Cemaat șeklinde geçmediğini, bu kavramen genelde, Ashâbu'l-Hadis, Eş'arilik ve Mâturîdîliği içine alan şemsiye bir kavram olduğunu belinti.

$\mathrm{Bu}$ oturumun müzakerecilerinden, Prof. Dr. Yusuf Şevki Yavuz, sunulan tebliğin, konu başlıklanyla ve mukayeseli bir şekilde ele alınmasının daha faydalı olacağın ifade etti. İman-amel aynmı yapmanın Ehl-i Sünnet için talihsizlik olduğunu ve bu durumun erdemsizliğe yol açtığın savundu.

Oturumun ikinci müzakerecisi, Prof. Dr. Sönmez Kutlu, kavram analizi yapilırken Ehl-i Sünnetin teolojik mi siyasal $\mathrm{m}$ olduğu üzeninde genişçe durulmasının önemine işaret etti. Bu kavramın hicri dördüncü asırdan itibaren kullanuldığının zannedildiğini, ama aslında İbnü Sa'd'in Tabakât'ında Ehl-i Sünnet ve cemaa kelimelerinin on, on beş yerde geçtiğini belintti. Bununla birlikte cemaat kavrammn daha önceleri kullanulduğmı belirterek, buna örnek olarak Ebû Hanife'nin Risâlei Osman el-Bettỉde söz konusu kavramın beş yerde geçtiğini ve bunun, ,tevhid ve nübüvvet gibi temel 
konularda tenzili inkar etmedikçe tekfir etmeyenler anlamunda şemsiye bir kavram olduğunu, Ehl-i Sünnetin, başlangıçta, önce cemaa sonra sevâdü'la'zam ve âmme şeklinde kullanıldı̆̆m, Ehl-i Sünnetin oluşmasında, Ashabü'r-Hadisten çok Ashabü'r-Rey'in etkili olduğunu açlkladi. Ancak daha sonra, Ashâbu'l-Hadisin hem cemaa hem de Ehl-i Sünnet kavramun tekeline almak suretiyle bu kavramlan marjinalleştirdiğini belirtti ve bu anlayşsın zamanla Rey taraftarlan üzerinde de etkili olduğunu savunarak, bunun Ehl-i Sünnetin hoş görülü ve birleştinci özelliğini zedelediğini ifade etti. Ashabu'rRey ve Mürcie arasındaki ilişkinin, Mâturî̀îliğe, Mürcie bulaşmasın diye Mâtunidiliğgin arka planının inkar edildiğini, bunun da, sorunlara akslcı bir şekilde çözüm üreten dinamik yapının göz ardı edilmesine yol açtı̆̆ıı belirtti. Özellikle selefî yaynlann arttığı ve selefilliğin baskın çıktığı son dönemlerde, selefîlik üzerinden Ehl-i Sünnetin anlaşılmaya çalhşıldığına dikkat çekerek, bunun sağılkı bir yaklaşım olmadığın ifade etti. Aynca, Ehl-i Sünneti, tek tip bir anlayş olarak görmenin, onun zenginliğini ve önemini küçümsemek olacağın; bu sebeple, Ehl-i Sünnetin çoğulcu, toparlayıcı, birleştirici, te'vilden dolayı telfir etmeyen anlayışnun korunması suretiyle yeniden bir Ehl-i Sünnet inşasına gidilmesini önerdi.

Prof. Dr. Bekir Topaloğlu başkanlğında yapılan ikinci oturumda, Doç. Dr. Mehmet Zeki İşcan, "Ehl-i Sünnetin Oluşumunda Öncü Şahsiyetler: Hasan Basri ve Ebû Hanife Üzerine Mülahazalar" adlı tebliğini sundu. İșcan, Hasan Basri ve Ebû Hanife'yi Ehl-i Sünnetin iki önemli şahsiyeti olarak ele aldı. O, bunlardan Hasan Basri’nin, dünyayı kötülediğgini, insanın ruhaniyetini muhafazaya gụ̧̈ yetirebilmesi için dünyadan el etek çekmesi gerektiğini savunduğunu söyleyerek bu anlayışa "öte dünyacı" (other wordly) adın verdi. İscan, Ebû Hanife'nin, dinin temel ilkelerine bağh kalarak, akliliği ve insaniliği esas alarak dini, evrensel ölçülerde tanumlamaya çaba sarf ettiğine işaret ederek, bunun "bu dünyacı" (this wodly) bir anlayıs olduğunu savundu. Zühri, Süfyan es-Sevri, Mâlik b. Enes, Şafi'î vb. kimselerin temsil ettiği Hadis taraftarlannın ise, bu dünyaya önem vermeyen, yeni bir meselenin ancak geçmişe referansla çözülmesi gerektiğini öngören gerilemeci' (declinizm) bir din anlayışını benimseyip savunduğunu ifade etti. $\mathrm{Bu}$ ü̧ görüsten, Ebû Hanife'nin görüşünün islamın genel prensiplerine daha uygun olduğuna işaret etti.

Oturumun birinci müzakerecisi olan Prof. Dr. Mustafa Öz, Ebû Hanife'nin Ehl-i Sünnetin büyük öncülerinden biri olduğu görüşünü destekledi ve onun görüslerinin daha tutarlı olduğu konusunda İşcan'la aynı görüşü paylaştığın ifade etti. Hasan Basri’nin, dünyay tamamen kötülemesini 
ve ona hiç değer vermemesinin, Kasas suresinin yetmiş yedinci ayetinde geçen, “ Allah'in sana verdiği şeylerde, ahiret yurdunu gözet; fakat dünyadaki payın da unutma ...” ayetine ters düştüğü gerekçesiyle doğru bulmayıp eleştirdi.

Oturumun ikinci müzakerecisi Prof. Dr. Ramazan Altıntaş ise, İşcan'ın Ehl-i Sünneti, "bu dünyacı", "öteki dünyacı" ve "gerilemeci” şeklinde bir tasnife tabi tutmasın eleştirdi. İslamm, hem bu dünyada hem de ahirette huzuru hedeflediğini belirtti.

Oturum başkanı Topaloğlu, konuşmalann Hasan Basri'nin görüşleri üzerinde yoğunlaşması dolayısıyla, Hasan Basri’ye isnat edilen bazı görü̧slerin ona ait olduğu konusunda şüphelerinin bulunduğunu, bu bakımdan onun hakkındaki iddialan iyi bir şekilde incelemeden değerlendirmede bulunmanın sağlıklı olmayacağına dikkat çekti

Prof. Dr. M. Saim Yeprem başkanlığında yaplan üçüncü oturumda, Doç. Dr. M. Sait Özervarlı, "Ehl-i Sünneti Meydana Getiren Ana Mezhepler ve Görüşler" adlı tebliğini sundu. Hakem olayından sonra Haricilerin şiddet içeren bir siyasi muhalefet yolunu benimsemesi üzerine, Ehl-i Sünnetin, Müslümanların tarihi mirasına sahip çlktığın, toplumsal çatışma ve kriz ortamuna meydan vermeyecek orta yolu benimsediğini belirten. Özervarl, Ehl-i Sünnetin, genelde, Ashabu'r -rey ve Ashabü'l-hadisi, diğer bir ifadeyle kelamcluk ve selefiliği kapsayan üst bir terim şeklinde kullanıldığın ifade etti.. Kelâmî Ehl-i Sünnetin, müdafaa, muhafaza özelliğinin yanı sıra değişime ve gelişime açık olduğunu; buna mukabil, Selefî Ehl-i Sünnetin ise, mutaassip muhafazakar, değişime ve gelişime kapalı olduğunu savundu. Daha sonra, Ehl-i Sünnetin, Ehl-i kable içindeki diğer büyük mezheplerden, temelde, akılnakil, iman-amel, zât-sıfat, irade-fïl, imamet-hilafet konulannda aynldıklannı mukayeseli olarak açıklamaya çalıştı.

Bu oturumun birinci müzakerecisi, Doç, Dr. Mustafa Sinanoğlu, Özervarlı'nın Ehl-i Sünnetin, Kelâmî ve Selefî olarak iki kısma ayrulmasının metot farklılı̆ından kaynaklandığı görüşünü destekleyici açıklamalarda bulundu. İkinci müzakereci Doç. Dr. Cağfer Karadaş, Mutezile'nin, itikâdî ve amelî konularda akulcı değil, nakilci bir mezhep olduğunu ve. her mezhebin, kendi radikal yorumunu doğurduğuna dikkat çekti.

Bu oturumda, Ayetullah Vaizzâde Horasânî tarafından "Ehl-i Sünnet ve Şia" adlı ikinci bir tebliğ sunuldu. Horasânî, tevhid, nübüvvet ve ahiret konusunda Ehl-i Sünnetle Şia'nın aynı görüşte olduğunu ve Kur'an'da, bütün müminlerin kardeş olduklan belirtilmesine rağmen Müslümanlann birlik ve 
beraberlik içinde yaşamadıklannı ifade etti, bu durumdan yakındı ve aynmculı̆ın, cehalet ile siyasetten kaynaklandığını ifade etti..

$\mathrm{Bu}$ oturumun birinci müzakerecisi, Doç. Dr. İlyas Üzüm, Horasânı̂nin aksine, Ehl-i Sünnetle Şia'nun, Tevhid (iman) ve nübüvvet konulannda aynı görüşe sahip olmadığını, İmâmiyye Şiasınun merkezinde imamet meselesi olduğunu belintti. Şï yazar Kulenîye göre, imamete inanmanun, imanun şartlan arasında yer aldığın, aynca, Şillerin ezan, Muhammeden rasulullah yerine, Aliyyen veliyyüllah şeklinde okumasına ve Ebû Hanife için, "imâmü'lerbâbi'l-vesvese" denildiğine dikkat çekti. Bütün bunlann, Horasânînin görüşünü çürüttüğünü söyledi. ikinci müzakereci Doç. Dr. İsmail Safa Üstün ise, Ehl-i Sünnet ve Şia arasında esas farkın imamet meselesi olduğuna vurgu yaparak bu konuda açılamalarda bulundu.

Prof. Dr. M. Akif Aydın başkanlığında gerçekleşen dördüncü oturumda, Prof. Dr. Ahmed Suphi el-Iyâd̂̀, tarafından "Ehl-i Sünnetin Usul Anlayı̧ı”" adlı bir tebliğ daha sunuldu. Burada, te'vilin, tenzile ve lügate uygun olması gerektiğini, Kur’an'da geçen "yed" kelimesinin kudret anlamına, "câe Allahu” sözünün Allah'in askeri anlamında olduğu belirtildi. Aynca, klyas ve icmanın sadece fikıhta geçerli olduğuna, bu ikisinin, akîde konusunda yeri olmadığına dikkat çekildi. Aklın esas oluşu ve kitaptan önce geldiği, imametin icmaen vacip olduğu ve ona uyulması gerektiği, devlet başkanınun ümmet tarafından seçilmesi gibi konulara temas edildi.

$\mathrm{Bu}$ oturumun ikinci tebliğcisi, Doç. Dr. Şükrü Özen, "Kelâmî tartışmalann Ehl-i Sünnet Usûlünün Oluşumundaki Rolü” adh tebliğinde, ilmî disiplinlerin henüz teşekkkül etmediği ilk dönemlerde, amel ve inançla ilgili tartışmalann kelâmî yönünün ağır bastığı, kelam ve usûlun sistematik bir disiplin haline gelmesinden sonra karşllklı etkileşim içinde geliştikleri ifade edildi. Usûl-ü fukıhta yapılan kelâmî tartışmalann daha çok kavramlar üzerinde yoğunlaştığına vurgu yapıldı. Ortaya konan bu tanımlamalardan hareketle, Ehl-i Sünnet kelâmının özelliklerini tespit etmenin mümkün olduğu belirtildi. ilk dönemlerden itibaren, Kur'an, sünnet, icmâ' ve kıyasın, usûlcüler tarafından deliller hiyerarşisi içinde, dinin asıllan olarak görüldüğü, usûl ilminin teşekküllünde, iç dinamiklerle birlikte, dış kaynaklann da etkisinin bulunduğu belirtildi. Ebû Hanife ve Şâfi gibi ills müctehid imamlann kelama sıcak bakmadıklanna dair rivayetlerin gerçeği yansıtmadığı belirtildi. İlk dönemlerdeki tartışmalann ortaya çıkardığı bazı temel usul konular açiklanmaya çalışıld.

Prof. Dr. Hazma Aktan başkanliğında yapılan altıncı oturumda, "Mezheplere Göre Akıl-Nakil İlişkisi” adh tebliğ, Prof. Dr. Vehbe ez- 
Zuhayî̀nin gelememesi sebebiyle sunulamadan müzakereye geçildi. Bu bölümün müzakerecilerinden Prof. Dr. Yaşar Aydınl, Selefiyye, Eş’ariyye ve Mâturîdîyyenin görüşlerini açıklamaya çalıştı. Mezhepler arasındaki farkın metot farklilığında kaynaklandığın belirtti. Mâturîlilikte, hem diğer İslam fırkalanna hem de İslam dışı düşüncelere cevap verilmeye çalışlldığı, Mâturîdînin akıl ile nakli birbirinin destekleyicisi kabul ederek Mutezileye yaklaştığı, Ehl-i Sünnet kelamcılannın, vahyi esas kabul ettikleri ve Eş'arilikte, hikmete ve düşünceye pek yer olmadığı; Mâturîlilikte ise, her şeyin hikmete göre yaratıldığına inanıldığı belirtildi.

Mustafa Fayda başkanlığında yapılan altıncı oturumun birinci bölümünde, Doç. Dr. Reşat Öngören'in hazırladığı "Ehl-i Sünnet'te Tasavvufun Yeri" adlı tebliğ, kendisi gelemediği için, Dr. Ramazan Yldınm tarafından okundu. Tebliğde, Ehl-i Sünnetin kapsamı açıklandıktan sonra, Ehl-i Sünnete göre tasavvufun bir değerlendirilmesi yapıld. Tasavvuf, ihlası gerçekleştirmeye yardım eden bir kurum olarak tanımlandı. "İhlas" ya da "ihsan" ın, iman ve amelden bağımsız olmadığına; aksine bu iki cüzün özünü ve zirvesini teşkil ettiği vurguland. Mutasavvıflan diğer gruplardan ayran temel özelliklerin başında, bilgiye ulaşma ve hakikati elde etme konusunda benimsedikleri keşif metodunun olduğu belirtildi. Tasavvufun nafile ve mubah alanı kapsadığı, bu nafilelerden sonuç alabilmek için farzlann da eda edilmesi gerektiği ifade edildi. Tasavvufun gaye olmadığı, ihlas/ihsan boyutunu gerçekleştirmek için bir vasıta olduğu vurgulanan tebliğde, tasavvufun, Müslüman olmak için şart olmadığınen altı çizildi. Dinin zahiri hükümlerinin önemli olduğu, rabıta, istimdat gibi şeyleri, vasıtadan daha ileriye götürmenin yanlışlı̆ına dikkat çekildi. Aynca, keşifle elde edilen bilgilerin sübjektif olduğunun asla göz ardı edilmemesi gerektiği ve bunlara, herkesin uymasının zorunlu olmadığ1, Kur'an'ın zahiri manalanın inkar etmenin, hem Ehl-i Sünnet alimlerinin, hem de mutasavvuflann onaylamadıklanna dikkat çekildi.

Müzakerecilerden, Doç. Dr. Hüseyin Sanoğlu, Gazali gibi mutasavvıflann keşif ile vahyin eşit görülmesinin ve keşfi, içtihattan üstün görmenin yanlış olduğunu belirterek, bu anlayışı eleştirdi. Dr. Necdet Tosun, Ehl-i Sünnet alimlerinin sufilere bakışı üzerinde durdu, ve Kur'an'ın temel prensiplerine aykın olmamak kaydıyla, farkh yorumlara açık olunmasın savundu.

Oturumun ikinci bölümünde, Prof. Dr. Hazma Aktan, "Ehl-i Sünnetin Yönetim Anlayıșın Oluşturan Temel Ilkeler” adh tebliğini sundu. Allah'ın Kur'an'da, adalete ve istişareye dayalı yönetim şeklini önerdiğini dikkat 
çekerek, meşveret ve adalet konusunu $\mathrm{Hz}$. Peygamberin uygulamalanndan ömekler vererek açiklamaya çalıştı. Hz Peygamberin, Bedir, Uhud, Hendek ve Tebük savaşlanna, arkadaşlanyla iştişare ederek karar verdiğine dikkat çekti. Istişareye her kesin katıldığın ve $\mathrm{Hz}$. Peygamberin herkesi dinlediğine ve onlann görüslerine değer verdiğini, kafalardaki bütün istifhamlan gidermeye çalıştığın belirtti. Hendek savaşından önce yapılan istişarede, Selman-i Farisi (r.a.)'in ileri sürdüğü, Medine'nin etrafına hendek kazalım fikrinin benimsendiğin; oysa o dönemin Arap kültüründe, Arap olmayan bir kimsenin adam yerine bile konulmadığına dikkat çekerek, Hz. Peygamber döneminde, dünya işlerinin, istişareyle yapıldığına, halkın kendi kendini yönetmesinin esas olduğuna vurgu yaptı. Yönetimin şeffaf olması, halkın yönetimin içinde bulunup soru sorabilme ve ögrenme hakkına sahip olması; aynca, yargıda, gelir dağllımında, makamda kısaca, her şeyde adaletin hakim olması gerektiği görüşünün hakim olması gerektiğini örnekleriyle açıklamaya çalıştı.

Sünnilerin, Hülafa-i raşidin dönemini idealize ettiklerine vurgu yapan Prof. Dr. Illhami Güler, halife seçimi gibi konularda kurumlaşmaya gidilmemesinin İslam toplumunda kargaşaya sebep olduğunu, bunun yerine yenilikçi, ihtiyaçlara cevap veren bir anlayışın hakim olması gerektiğini savundu. Prof. Dr. Ali Ôzek ise, Hz. Peygamberin biri nübüvvet diğeri siyaset olmak üzere iki vasfının bulunduğunu ve o (s.a.s.)'in her şeyi adalet ve istişareyle yaptığını; ancak Hz. Ebû Bekir'in kendi yerine $\mathrm{Hz}$. Ömer'i aday göstermesini doğru bulmadığın, bunun, Müslümanlann öz iradesiyle seçim yapmasın engelleyen bir unsur olduğunu, $\mathrm{Hz}$. Ömer'in de, Peygamberimizin aksine, hanımlanı biatini almadı̆ın savundu. Bunun üzerine, oturum başkanı Prof. Dr. Mustafa Fayda, Hz. Ömer'in, Hz. Peygamberi en iyi anlayan ve onun sünnetini en iyi uygulayanlardan biri olduğuna işaret etti.

Prof. Dr. İbrahim Kafi Dönmez başkanlığında yapılan altıncı oturumda, ilk olarak, Prof. Dr. Hasan Hanefî "Günümüz Selefî Akımlan ve Tarihî Selefilik ile İlişkisi” adlı bir tebliğ sundu. Müslümanlann geçmiş tecrübelerinden yararlanması gerektiğini, ancak, bunu yaparken tarihin derinliklerinden kaybolmadan sorunlara çözüm arayan, yenilikçi ve dinamik bir anlayışın geliştirilmesini istedi. Ehl-i Sünnet mezhebine ve yetmiş üç fırka hadisine eleştiriler getiren Hasan Hanefi, Müslümanlann tarih boyunca sıkıntıya düşmelerinin en büyük sebebinin mevcut Ehl-i Sünnet anlayışı olduğunu ifade etti, mezhep aynmculhğın tehlikesine dikkat çekti, kurtuluşunun ancak, akılcı, yenilikçi, dinamik ve ihtiyaçlara cevap verebilen Selefî anlayışa sahip olmakla mümkün olabileceğini ifade etti. 
Müzakerecilerden Prof. Dr. M. Hayri Kırbaşoğlu, Hasan Hanefi'nin görüşlerini destekleyici açıklamalarda bulundu. Ehl-i Sünnetin furka-i Naciye anlayışıyla, Müslümanlara bir şey kazandırmadığını aksine, onlan parçalayıp mahvettiğini, bundan kurtulmak için Hasan Hanef'nin açıkladığı Selefî düşüncenin hakim olmasına vurgu yaptı ve onun görüşlerini açıklamaya çalşstı. Bu oturumun ikinci müzakerecisi Doç Dr. Mehmet Büyükkara ise, Hasan Hanefînin Selefilik tanımlamasına çekincelerini belirtti ve selefiliğin tarihî süreci üzerinde durdu. Cemalettin Efgani, Mevdudi, Reşit Ruza, Muhammed Abduh ve Seyit Kutup vb. alimlerin Selefî olduğunu belirten Büyükkara, bu anlayışın Reşit Rıza ile Vahhabiliğe yaklaştığını ancak Vahhabilik adının toplumda, antipati uyandırmasında çekinildiği için Selefî adında karar kılındığın ifade etti. Selefî anlayıșın özelliklerini, hadis merkezli zahiri yorumcu, kurtuluş̧̧uluk, tekfirci ve uzletçi şeklinde sıraladı.

$\mathrm{Bu}$ oturumun ikinci tebliğcisi, Prof. Dr. İlyas Çelebi, "Geleneksel Ehl-i Sünnet Anlayışının Günümüzde Yeniden Değerlendirilmesi” adlı bir tebliğ sundu.. Ehl-i Sünnetin başlangıçta aynı anlayışı paylaşanlan ifade eden şemsiye bir kavramken, daha sonra, Ehl-i Bid'ata karşı mezhep imamlarınun içtihatlanna dayanan din anlayışını savunan furka-i Naciye haline dönüş̧tïğünü söyledi. Tarihi süreç içinde, Ehl-i Sünnet kavramunun anlamlan üzerinde durdu ve zaman içinde bu kavramda, bir takım anlam kaymalan olduğuna dikkat çekerek, bunlan, örnekleriyle açıklamaya çalıştı. Bugün Ehl-i Sünnet kavramunun, diğer mezhepleri dışlayan olumsuz bir hale dönüştüğünü, bu nedenle, bunu kullanmaktan aslında vazgeçilmesi gerektiğini, ancak, bunun zor bir iş olduğunu söyleyerek, alternatif olarak Ehl-i Sünnet kavramının içinin yeniden doldurulması gerektiğini ifade etti.. Bunun da, ancak, öz güvenin oluşması, özgürce düşünceyle, banş ve huzuru isteyerek, taklit ve taassuptan uzak kalarak, dengeli ve tutarl bir anlayışın hakim olmasıyla mümkün olduğunu açıklamaya çalıştı.

Bu tebliğin müzakerecileri Doç. Dr. Erkan Yar, Müslümanlanın başına gelen skkıntılann, Ehl-i Sünnet ve'l-Cemaat anlayışına sahip olmasından kaynaklandığını tekrar ederek bu konuya vurgu yaptı. ve Doç. Dr. Tahsin Görgün ise, toplantı boyunca Ehl-i Sünnet anlayışının kötü bir imajının çizildiğini, onun Müslümanlann geri kalmasının tek suçlusu gösterildiğini, fakat bunun böyle olmadı̆ın ifade etti. Bu bağlamda, Ehl-i Sünnetin istitaat konusunda, Mutezileden çok daha ileri bir anlayışa sahip olduğunu ifade etti.

Prof. Dr. M. Saim Yeprem, Prof .Dr. İbrahim Kafi Dönmez, Prof. Dr. Hasan Hanefi, Prof. Dr. Mahmut Kaya ve Prof. Dr. M. Hayri Kırbaşoğlu 
tarafından, üç gündür sunulan tebliğ ve müzakerelerin genel bir değerlendirilmesi yapıldı. Sonuçta, şu görüşlere varildı.

İslamın bir bütün olduğu ve çeşitli gruplara aynlarak bu bütünliğüü zedelenmesine yol açacak girişimlerden uzak durulması benimsendi Bunun,birlik ve beraberliğin ve hoş görü ortamunun temini için şart olduğu vurguland. Bunun için, islam'ın genel prensipleri etrafında tek şemsiye altında toplanulması gerekli görüldü. Bununla birlikte Kur'an'in temel prensipleri çerçevesinde kalmak şartıyla, çeşitli düşünce ve eğlimlerin olmasınun tabii bir durum olduğu, bunun ashnda bir çeşit zenginlik olduğu dile getirildi. Ancak, hiçbir mezhebin veya grubun islam'la özdeşleştrirlmesinin doğru olmadığına vurgu yapıldı. Bu sebeple, Müslümanlarn hem kendi aralannda hem de diğer din ve düşüncelere karş̧ı hoş görülü ve saygul olmaları istendi. Bunun huzur ve sükunun sağlanmasında önemli katkısının olacağı belirtildi. Aynca dünyada daha rahat yaşayabilmek için yardımlaşmanın ve gelişime açık olmanın önemine dikkat çekildi.

\section{Değerlendirme}

Geniş ve dinamik bir dinleyici kitlesinin katıldı̆̆ bu toplantıya ülkemizdeki çeşitli üniversitelerden değerli ilim adamlannın yanı sıra Suriye, Mısır ve İran'dan birer uzmanın katlması olumlu olmakla birlikte, doğu ve batı dünyasından hiç kimsenin bulunmaması dikkat çekti. Aynca, gerek Türkiye içinde gerekse yurt dışında konularnnda uzman olan kişilerin daha geniş katılımı sağlanabilse daha yararlı olabilirdi. Yine, böylesine uluslar arası bir sempozyumun fiziki şartlan daha uygun olan - mesela amfi türü konferans salonlan gibi- bir yerde yapulabilirdi. Yine, özellikle genç akademisyenlere daha fazla söz hakkı verilebilirdi. Böylece hem onlann heyecanlan, toplantıya bir zenginlik katard, hem de onlann önü açılmış olurdu. Bütün bunlara rağmen böylesine geniş ve önemli bir konuyu kurk civannda ilim adamyla tartı̧̧maya açmak ve bu konuda bir ilkin gerçekleştirilmiş olması açısından İslam Araştırmalan Vakfı (ISAM)'nun organize etmis olduğu bu toplantı takdire şayandır. Ayrıca, toplantıda sunulan her tebliğden sonra, tebliğlere ilişkin sorulan sorular ve yapılan değerlendirmeler dinleyicilerin de toplantrya aktif katulumlannı sağlaması, yine aynca oturum baskkanlarının zaman zaman etkin katulmlarda bulunmaları da toplantının dikkat çeken yönlerinden birisiydi.

Toplantının genelinde, Ehl-i Sünnet'e karşı olumsuz bir tavır alınması, özellikle de, Müslümanlann ahlaki yozlaşmasının, Ehl-i Sünnetin Hanefí- 
Maturidî düşünceye ait, amel-iman ayrumı prensibine bağlanması, bu konunun ilk kaynaklara inilerek ve yeteri kadar incelenmediğini gösterdi. Çünkü, iman-amel aynm, Ehl-i Sünnet olarak gösterilen gruplar içinde sadece Hanefî-Mâturîdî düşüncede söz konusudur. Konușmacılann da ifade ettiği gibi Ehl-i Sünnet Ashabu'l-Hadis, Selefilik, Eş'arilik ve Mâturîdîlil olarak gruplara ayrılmıştır. Kaldı ki, Kutlu'nun da ifade ettiği gibi daha sonra, Ashabu'l-hadis, Rey taraftarlan üzerinde bir hayli etkili olmuştur. Başka bir ifadeyle, Ehl-i Sünnet sadece Hanefi- Mâtunîlîlerden meydana gelmediği gibi, zamanla Mâturîdîliğin içi Hadiscilerin itikaddaki mezhebi olan Eş’arilikle doldurulmuştur. Bütün bunlarla birlikte, İman-amel aynm, durup dururken ortaya çıkmış basit bir mesele değildir. Bu konunun daha iyi anlaşılabilmesi için, şu iki noktanun bilinmesi büyük önem arz etmektedir. Bunlardan birincisi, Sıffın ve Cemel savaşlanndan sonra büyük günah işleyenin durumu konusunda Müslümanlar ihtilafa düştüler, Hariciler, büyük günah işleyen her kesin, dinden çıktığın iddia ettiler, kendileri gibi düşünmeyen Müslümanlan öldürmeye başladılar. Bu durum, İslam toplumunda karışıklığa ve huzursuzluğa neden oldu. İkincisi ise, hadis taraftarlan ameli imanun bir parçası olarak gördükleri için, bütün amelleri yenine getirmeyenlerin mümin olamayacağın söylüyorlardı. Yine, Mutezile, bu konuda büyük günah işleyen bir müslümanın konumunu, tartışmaya açarak onun mümin ile kafir arasında bir yerde olduğunu ileri sürüyorlardı. Bu durum karşısında, kafası karışan Müslümanlar, acaba ben gerçekten Müslüman mıım, dinden çıktım m? Gibi sorularla bocalamaya başlamışlardı., Bu sebeple Hadis taraftarlan, göğsünü gere gere "Ben gerçekten müminim" diyememiş, günahsız insan olamayacağ için bu durum karşısında psikolojik bunalıma düşmüş., kendinden emin olmadığ için "inşallah müminim" demeyi tercih etmişti. Bütün bu olaylar, Müslümanların psikolojisinin bozulmasına sebep olmuştu. Iş̧te tam bu sırada, Mürcî̀ düşünceye sahip Ebû Hanife gibi şahsiyetler İmanın kalp ile tasdik olduğunu, amellerin ise, imanun gereği olduğunu yani dinde asıl olanın iman etmek olduğunu, amel etmenin gerekli fakat mümin olmak için şart olmadığı görüşünü benimseyerek Müslümanları hem acaba ben Müslüman miym değimliyim? tereddüdünden, hem de hiç kimsenin günahından dolayı dışlanmaması gerektiğini savunmuşlardır. Bu açıklamalardan anlaşıldığı üzere, iman ile amelin ayn şeyler olduğunun belirtilmesi, Müslümanlann içine düşmüş olduklan, psikolojik ve sosyolojik bunalımdan kurtulmasına yardımcı olmuştur. Buna rağmen, bu gerçeğin göz ardı edilmesi, onlara karşı haksılık olacağı kanaatindeyiz. Çünkü, her konu, ortaya çıktığı dönemin şartlan içinde değerlendirilirse bir anlam ifade eder ve doğru anlaşlır. Iman-amel ayıımının 
Müslümanlan ahlaksızlaştırdığı iddiasına gelince, Hanefî-Mâturîdî düşüncenin temelini atan Ebû Hanife ve onun görüşlerini sistemleștiren Ebû Mansur elMâturîdî, dinde asıl olan şeyin iman olduğunu belirtmekle birlikte, kesinlikle, amelsiz imanı savunmadılar, hatta onlar, insanın en küçük bir günahtan dolay bile Allah'ın gazabına uğrayabileceğini açık bir şekilde ifade ettiler. Her ikisi de, imanla birlikte amelin de ihlash bir şekilde yerine getirilmesine son derece önem vermişlerdir. Bu açılklamalar, iman-amel ayrum konusunda Ehl-i Sünnetin Rey kanadınun eleştirilmesini değil, takdir edilmesi gerektiğini açıkça göstermektedir. Nitekim, Sönmez Kutlu, tebliği müzakere ederken, Mâturîdîliğin arka palanının reddedilerek, akıla ve hoşgörücülüğün yanlış anlaşıldığın belirterek bu konuya dikkat çekmiştir.

Yine, bilindiği gibi Ebû Hanife'nin benimsemi,̧ olduğu metodu, insan haklanuın ve kamu menfaatinin korunmasını esas almakla birlikte, kolaylaştıncı ve her şeyin-mümkün olan- en iyisini yapmayı hedeflemektedir. Başka bir deyişle, o, ferdin haklannın korunması, halkın menfaati, kolaylık ve benzeri düşüncelerle gerekirse kıyası bile terk edip insanlar için en uygun olanı aramaktadır. Aynca, Şafiye göre, içtihadın zirvesi kyyasken, Ebû Hanife'ye göre ise, kıyas, içtihadın başı saylmaktadır. Yine, Mâturînîye göre, akıl, insanı her türlü erdeme kavuşturur. Yine, her şeye rağmen birlik ve beraberlik içinde hoş görülü bir yaşam sürmek Mürcie'nin ve devamı olan Mâturîdîliğin esasını teşkil etmektedir. Buna rağmen, Ehl-i Sünnet içinde hatta Mâtunî̉ilik içinde bile Ebû Hanife ve İmam Mâturîdî anlaşlamamışır. Bütün bunlar, Ehl-i Sünnet toplantısında, hemen hiç yer verilmeyen Mâturîdîliğin iyi anlaşılmasına ne kadar ihtiyaç olduğunu göstermektedir. 